\title{
Development of a non-isothermal method for determination of diffusional parameters
}

\author{
LÍlIA A. MOREIRA, FERNANDA A.R. OLIVEIRA*, \\ TERESA R. SILVA \& JORGE C. OLIVEIRA \\ Escola Superior de Biotecnologia, Universidade Católica Portuguesa, Porto, Portugal
}

\section{Summary}

A non-isothermal method for determination of diffusional parameters was developed. The dependence of diffusivity on temperature was described by an Arrhenius type equation, with the pre-exponential factor and the activation energy as parameters. These parameters were obtained by optimization of the fit between experimental and theoretical values, using the Simplex method of minimization. Equilibrium conditions were described with a constant unit partition coefficient. This model was applied to the diffusion of acetic acid into turnips. Results compared well with values obtained with the conventional method, using a set of experiments at isothermal conditions. The non-isothermal method has significant advantages, namely the need for much less experimental data and better insight into the statistical significance of the results.

\section{Keywords}

Acidification, blanching, diffusion coefficient, Fick's 2nd law, leaching, turnip (Brassica Rapa).

\section{Introduction}

Mass transfer in food processes, such as leaching and acidification, generally occurs under non-isothermal conditions. Mass transfer in these conditions can be usually described as a simple diffusional process controlled by Fick's 2nd law (Schwartzberg \& Chao, 1982; Rodgers et al., 1984; McCarthy \& Heil, 1988; Oliveira, 1988). The adequate description of the process requires both the determination of the diffusion coefficient for the particular food/solute system and the study of its dependence on temperature. Previous studies approach this problem by analysing the process at different constant temperatures (Rodgers et al., 1984; Luna \& Garrote, 1987; Garrote et al., 1988; Oliveira, 1988). A diffusion coefficient is obtained for each temperature and the set of diffusivity values is then correlated with temperature using an Arrhenius type equation. The relevant parameters are therefore the activation energy and the pre-exponential factor of the diffusivity versus temperature relationship. This two step method is usually considered to produce good results but requires a significant number of experiments (at least one for each temperature). Most works are based 
on results obtained at 3 different temperatures only (Rice \& Selman, 1984; Kincal \& Kaymak, 1990; Rodgers et al., 1984). However this implies a large error in the determination of the parameters, leading to confidence intervals eventually as large as the parameters themselves (Labuza \& Kamman, 1983). An analysis involving a significant number of temperatures and samples at each temperature would be, however, expensive and time consuming.

Equilibrium conditions are also important in the modelling of a diffusional process, although seldom referred to. Most works assume that equilibrium is achieved when the concentration of the solute in the food equals the external solution concentration (Potts et al., 1986). This assumption is frequently not explicit and rarely verified. However, if a partition of solute occurs between the food and the solution, equilibrium can be described simply by a partition coefficient (Crank, 1979). This parameter must, however, be obtained experimentally.

This study introduces a non-isothermal method for determination of diffusional parameters. Non-isothermal methods were first introduced by Rogers (1963) and reported in the literature for the studdy of reaction kinetics (Rhim "et al., 1989a, Nunes et al., 1991) and for kinetics of colour change (Rhim et al., 1989b). In these works first-order rate, Arrhenius type dependence of rate constant with temperature and temperature linearly increasing with time were considered. A similar procedure can be applied to diffusional processes. When a diffusional process occurs under non-isothermal conditions, the amount of material that has diffused after a given time provides information not only on the diffusional process but on its dependence on temperature as well. However, mass transfer processes in these conditions can rarely be described by first order kinetics and therefore the models suggested in the referred works cannot be directly applied. Computer time requirements for these models are higher but this drawback is clearly compensated by the reduction of experimental requirements. Furthermore, thermal lag effects are reduced, increasing the accuracy of the results.

The main objectives of this work were: (i) to develop a non-isothermal method for determination of diffusional parameters and (ii) to validate this model experimentally by comparing the results obtained for the diffusion of acetic acid into turnip cubes using the model developed, with results obtained with isothermal methods.

\section{Mathematical considerations}

Assuming acidification processes follow a simple diffusional mechanism, acid intake by turnips can be described by the solution of Fick's second law, for the specific boundary conditions of the process. The total amount of solute at time $t, M_{t}$, in a cube of dimension $2 \mathrm{~L}$, initially free of solute and subject to diffusion from a well stirred, constant temperature bath of limited volume, can be calculated by (Crank, 1979, Moreira et al., 1992):

$$
\frac{M_{t}}{M_{\infty}}=1-\left(\sum_{n=1}^{\infty} \frac{2 \alpha(1+\alpha)}{1+\alpha+\alpha^{2} q_{n}^{2}} \operatorname{EXP}\left(-\frac{D q_{n}^{2} t}{L^{2}}\right)\right)^{3}
$$

where $D$ is diffusivity and $q_{n}$ are the non-zero positive roots of:

$$
\tan \mathrm{q}_{\mathbf{n}}=-\alpha \mathrm{q}_{\mathbf{n}}
$$

$\alpha$ is related to the fractional uptake of solute and corresponds to: 


$$
\alpha=\frac{\mathrm{V}_{\mathrm{b}}}{\mathrm{V}_{\mathrm{p}} \mathrm{K}_{\mathrm{p}}}
$$

where $V_{b}$ and $V_{p}$ are the volumes of the bath and cube respectively, and $K_{p}$ is the partition coefficient.

The acid content at equilibrium, $\mathbf{M}_{x}$, can be obtained by a simple mass balance (Moreira et al., 1992):

$$
\mathrm{M}_{\varkappa}=\frac{\mathrm{V}_{\mathrm{b}} \mathrm{C}_{0}}{(1+\alpha)}
$$

where $C_{0}$ is the initial concentration of acetic acid in the bath.

In the conventional isothermal (two step) method one value of the diffusivity is obtained for each experiment at each temperature. It was experimentally verified that the partition coefficient did not depend on temperature or concentration and its average was close to unity. Therefore diffusivity was the only parameter to be optimized. The Simplex method of minimization was used on the residual (Res) between experimental and theoretical data expressed as:

$$
\operatorname{Res}=\sqrt{\sum_{i=1}^{N}\left(M_{t}-M_{t}^{e}\right)^{2}} \text {. }
$$

The dependence of diffusivity on temperature (T) was described by an Arrhenius model:

$$
\mathrm{D}=\mathrm{D}_{0} \mathrm{EXP}\left(-\mathrm{E}_{\mathrm{a}} / \mathrm{RT}\right)
$$

where $E_{a}$ is activation energy.

To minimize the effects of the collinearity between these parameters and to accelerate convergence, eqn (6) was rewritten as suggested by Nelson (1983):

$$
D=\operatorname{EXP}\left[\delta-\frac{E_{a}}{R}\left(\frac{1}{T}-\beta\right)\right]
$$

where:

$$
\delta=\ln \left(D_{0}\right)-\frac{E_{a}}{R} \beta
$$

and

$$
\beta=\frac{1}{N} \sum_{i=1}^{N}\left(1 / T_{i}\right)
$$

The activation energy, $E_{a}$ and the dummy variable $\delta$ were then determined by a non-linear regression, based on the Simplex method, of the diffusivity values with temperature.

In the non-isothermal method, an estimate of the pre-exponential factor and activation energy is obtained directly as a result of one single fit: a one-step procedure. The non-isothermal and two step isothermal methods are therefore not directly comparable. An alternative is the application of a single non-linear regression to all isothermal data, estimating $\mathrm{D}_{0}$ and $\mathrm{E}_{\mathrm{a}}$ without calculating diffusivities at each temperature (the one step isothermal method). This is actually the best method for the prediction of the Arrhenius parameters from isothermal data since it gives both 
unbiased and precise estimations. It is theoretically the most appropriate method since it does not estimate unnecessary parameters and one does not need to be too concerned about the implications of the regressions on the regression parameters (Haralampu et al., 1985; Cohen \& Saguy, 1985). However, this method has not yet been applied to diffusional studies. This procedure has been suggested and used by Haralampu et al. (1985) with good results, for first order kinetics. The major limitation is the computational complexity, requiring more sophisticated techniques. This is obviously even more relevant for diffusional studies, since the diffusion equation is much more complex than first order kinetics.

Therefore, in our study, both methods (one step and two step) were applied to the isothermal data.

Under non-isothermal conditions the dependence of the diffusivity on temperature must be considered in the basic equation as well. This relation can be described as a dependence of diffusivity on time. In this situation, the solution of Fick's second law for constant D still applies, provided an average value, $D^{\prime}$, is used (Crank, 1979):

$$
D^{\prime}(T)=\frac{1}{t} \int_{0}^{t} D(t) d t
$$

If the diffusion coefficient varies with temperature following an Arrhenius type equation, eqn (10) can be rewritten as:

$$
\mathrm{D}^{\prime}(\mathrm{T})=\frac{1}{\mathrm{t}} \int_{0}^{\mathrm{t}} \mathrm{D}_{0} \operatorname{EXP}\left(\frac{-\mathrm{E}_{\mathrm{a}}}{\mathrm{RT}(\mathrm{t})}\right) \mathrm{dt}
$$

The integral can only be solved numerically, once the relationship between $\mathrm{T}$ and $\mathrm{t}$ is known. A linear relationship is the most common, having the advantage of giving equal weight to all temperatures. An approximately linear temperature increase was used in this study.

Two parameters, $D_{0}$ and $E_{a}$, need therefore to be considered for optimization of the fit between experimental and theoretical values, and the Simplex method of minimization was used for this. Similarly, the optimization was carried out in terms of $E_{a}$ and the dummy variable $\delta$.

These calculations were performed by a computer program written specifically for this purpose in the FORTRAN 77 language.

\section{Materials and methods}

\section{Turnip samples}

Turnips (Brassica Rapa) were obtained from a Ministry for Agriculture farm, located in the North of Portugal. All turnips were from the same harvest. On arrival at the laboratory they were characterized chemically (water, sugar, protein, fat, vitamin $\mathrm{C}$, ash and fiber content and $\mathrm{pH}$ ) and physically (mass, density, volume and surface area) and stored in a cold room at $0{ }^{\circ} \mathrm{C}$ and $95 \% \mathrm{RH}$, for up to 1 month. A proximate analysis is given in Table 1. Before each experiment the turnips were washed, hand peeled and cut in $2.5 \mathrm{~cm}$ cubes. 
Table 1. Proximate analysis of the turnips

\begin{tabular}{|c|c|c|}
\hline Component & $\begin{array}{l}\text { Content } \\
\text { ( }\left(\mathrm{g} 100 \mathrm{~g}^{-1} \text { of turnip) }\right.\end{array}$ & 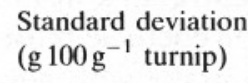 \\
\hline Water & 93.1 & 0.7 \\
\hline Reducing sugars & 3.6 & 0.3 \\
\hline Proteins & 1.2 & 0.1 \\
\hline Fat & 0.7 & 0.2 \\
\hline Fibre & 1.2 & 0.3 \\
\hline Vitamin C & 0.018 & 0.003 \\
\hline Ash & 2.4 & 0.05 \\
\hline
\end{tabular}

$\mathrm{pH}=6.1 \pm 0.2$

\section{Acidification experiments}

\section{Isothermal method}

The procedure used was the one reported by Moreira et al. (1992). Covered flasks containing $50 \mathrm{ml}$ of $0.2 \mathrm{M}$ acetic acid were immersed in a thermostatic bath and shaken by a reciprocating motion. Twelve different temperatures between 20 and $100^{\circ} \mathrm{C}$ were considered. Acetic acid concentration was checked with standard $\mathrm{NaOH}$ $0.2 \mathrm{~m}$. After the acetic acid solution had reached the temperature of the bath, one turnip cube was immersed in each flask and held there for given periods of time up to $4 \mathrm{~h}$. The turnip cubes had previously been wrapped in para-film and pre-heated over the bath to the required temperature. This procedure was required in order to avoid thermal lag effects, particularly at high temperatures. After removal of each cube, the acid solution from the respective flask was titrated. The amount of acid

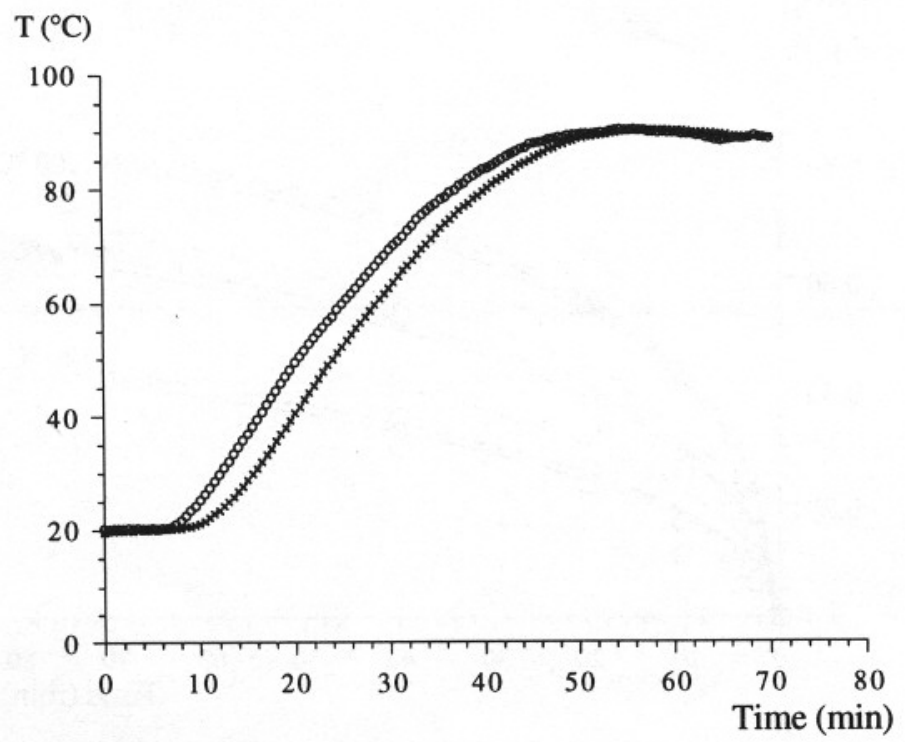

Figure 1. Typical temperature histories in the solution and at the turnip centre. $o$, bath; $x$, turnip centre. 
uptake by each cube was calculated by a simple material balance, based on the initial and final concentrations in the solution.

The diffusion coefficient for each temperature was obtained by fitting experimental values of acid intake with eqn (1).

\section{Non-isothermal method}

The procedure was similar to the one previously described, except that the bath temperature was initially set-up at $20^{\circ} \mathrm{C}$. After immersion of the cubes, the bath temperature was increased with time. This increase was approximately linear (Fig. 1 shows a typical example). An additional flask containing a turnip cube was used to provide information on the temperature history during the process: a thermocouple was inserted in the centre of the cube and another one in the acid solution. These thermocouples were linked to a computer data acquisition system. The acquisition time interval was $30 \mathrm{~s}$. Three runs were carried out.

\section{Equilibrium data}

Equilibrium values were obtained for each temperature. The experimental set-up was the same as for isothermal experiments. Equilibrium was assumed to occur when the acetic acid solution concentration in the flask remained constant with time and this took $5-27 \mathrm{~h}$, depending on temperature.

\section{Results and discussion}

Results obtained in the isothermal experiments showed that the process could be described as simple Fickian diffusion. Some typical results are shown in Fig. 2, where the experimental results are compared with predictions made using parameters

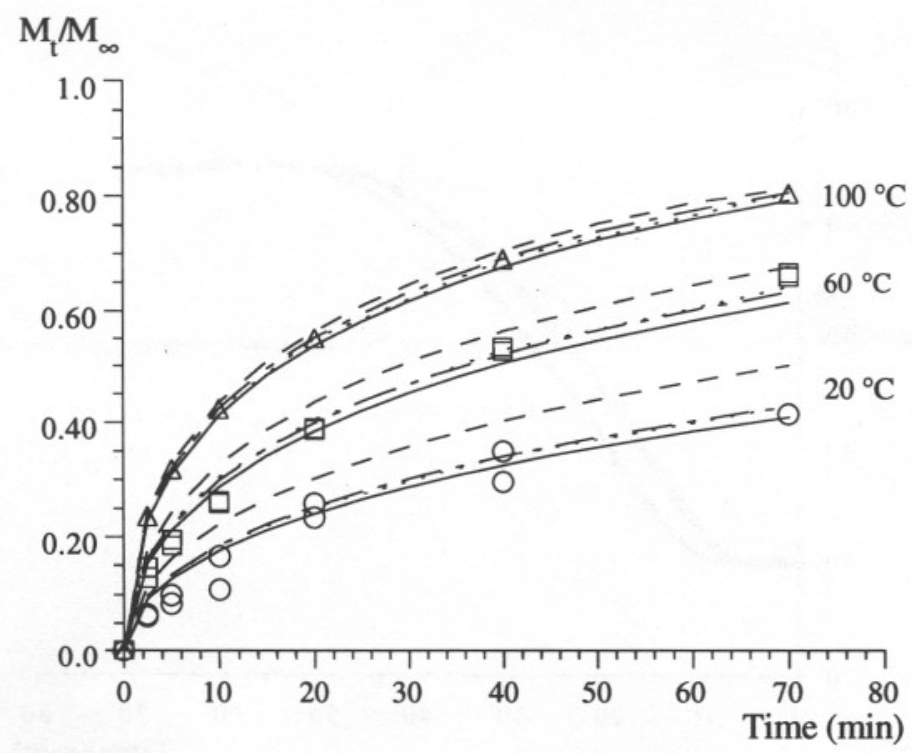

Figure 2. Acid uptake by turnip cubes under isothermal conditions at $20^{\circ} \mathrm{C}(\circ), 60^{\circ} \mathrm{C}(\square)$ and $100^{\circ} \mathrm{C}(\triangle)$. Predictions made with the parameters obtained with the one step isothermal method (continuous line) and with each of the non-isothermal experiments (dashed lines) are shown. 
obtained from the three different non-isothermal experiments. The partition coefficient was not dependent on temperature and values obtained averaged unity. Similar results were reported by Moreira et al. (1992), for a similar system. This value was then assumed for all temperatures, although it did not correspond to the best fit in most of the cases. However this is the more common approach and results were quite acceptable. The variation of diffusivity with temperature correlated well with an Arrhenius equation (Fig. 3). The values of $E_{a}$ and $D_{0}$ were similar for both isothermal methods: $19.5 \mathrm{~kJ} \mathrm{~mol}^{-1}$ and $0.188 \times 10^{-5} \mathrm{~m}^{2} \mathrm{~s}^{-1}$ when calculated from individual $D$ values at each temperature (two step) and $20.9 \mathrm{~kJ} \mathrm{~mol}^{-1}$ and $0.307 \times 10^{-5} \mathrm{~m}^{2} \mathrm{~s}^{-1}$ when calculated directly from all the data (one step).

The acid intake by the turnips under non-isothermal conditions was between the isothermal intakes observed at the extreme temperatures $\left(20\right.$ and $\left.100^{\circ} \mathrm{C}\right)$, as would be expected. This can be seen by comparing Figs 2 and 4 . In terms of mass transfer rate however, the two isothermal and the non-isothermal curves show a similar behaviour (Fig. 5). Mass transfer rate depends both on the diffusion coefficient (temperature) and on the concentration gradient. At constant temperature, as time proceeds, the concentration gradient decreases and it can be observed that mass transfer rate decreases dramatically. This effect is more significant at high temperatures because diffusion occurs at a higher rate and therefore the concentration gradient decreases faster. When temperature increases with time an opposite effect occurs and therefore one could expect that the variation of diffusion rate would be different for the non-isothermal experiments. However, it can be concluded from Fig. 5 that this effect was not considerable. This behaviour differs considerably from

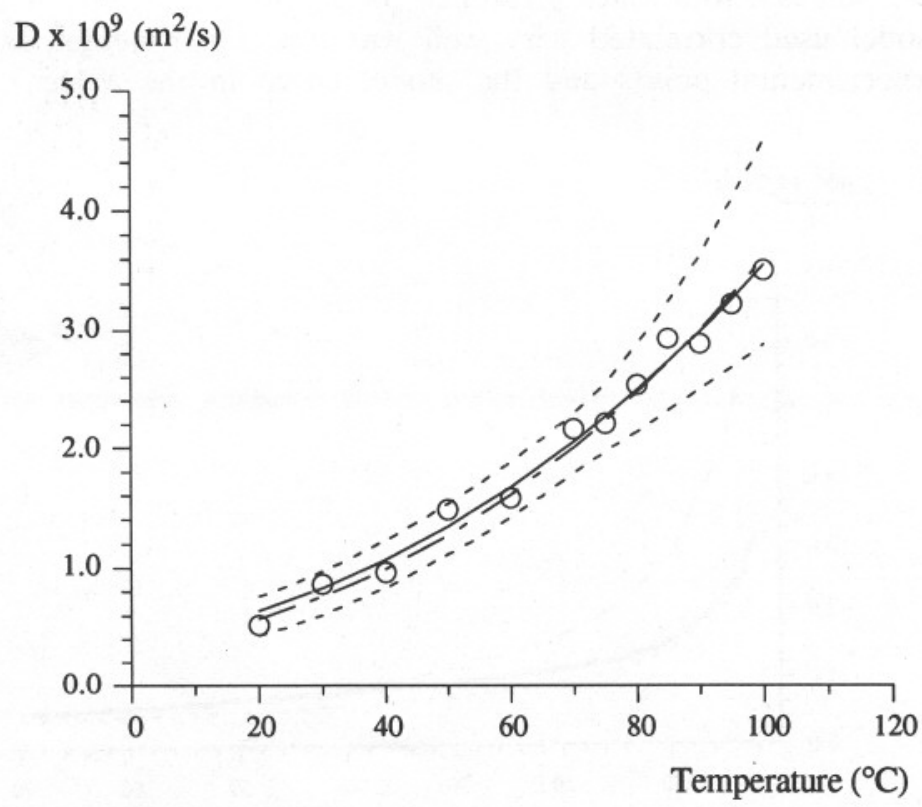

Figure 3. Variation of the diffusion coefficient $\left(D_{0}\right)$ with temperature obtained from the isothermal methods. The confidence interval refers to the one step method.

०, experimental points; ----, $90 \%$ confidence interval; $\_$, two step; $-\ldots$, one step. 


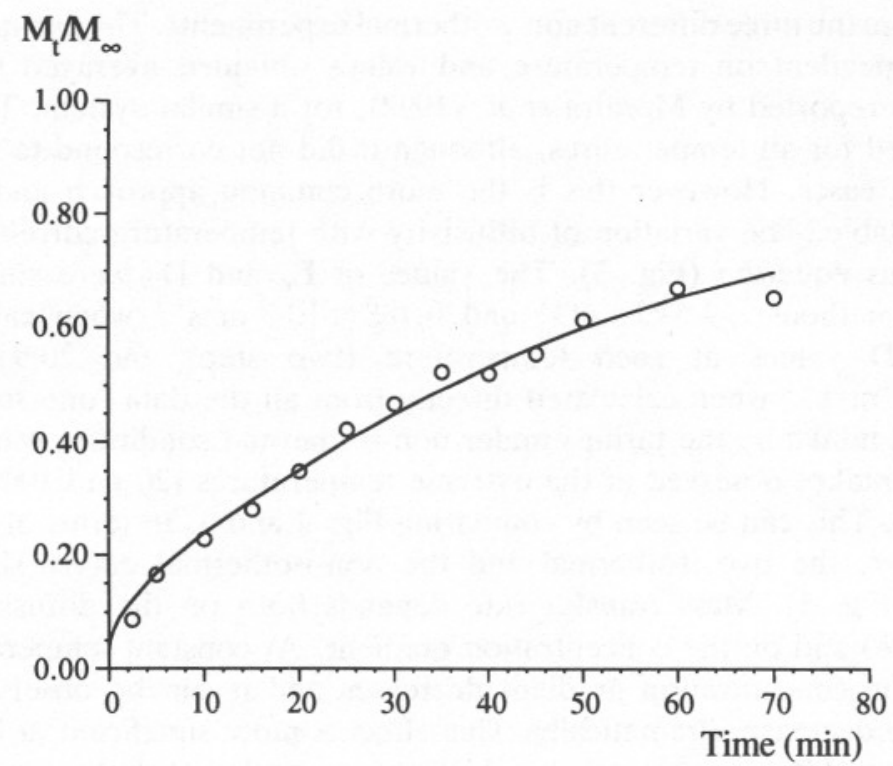

Figure 4. Acid uptake by turnip cubes in a typical non-isothermal experiment. $\circ$, experimental points; $\longrightarrow$, model.

that observed with first order reaction kinetics. Rhim et al. (1989a) reported that the effect of temperature was so important that the concentration history curves showed a concave shape. This difference may be explained by the difference between the activation energies of reaction kinetics and of diffusional processes: reaction kinetics usually have values 4 to 5 times greater.

The model used correlated very well with the experimental data. Residuals between experimental points and the model curve in the three non-isothermal

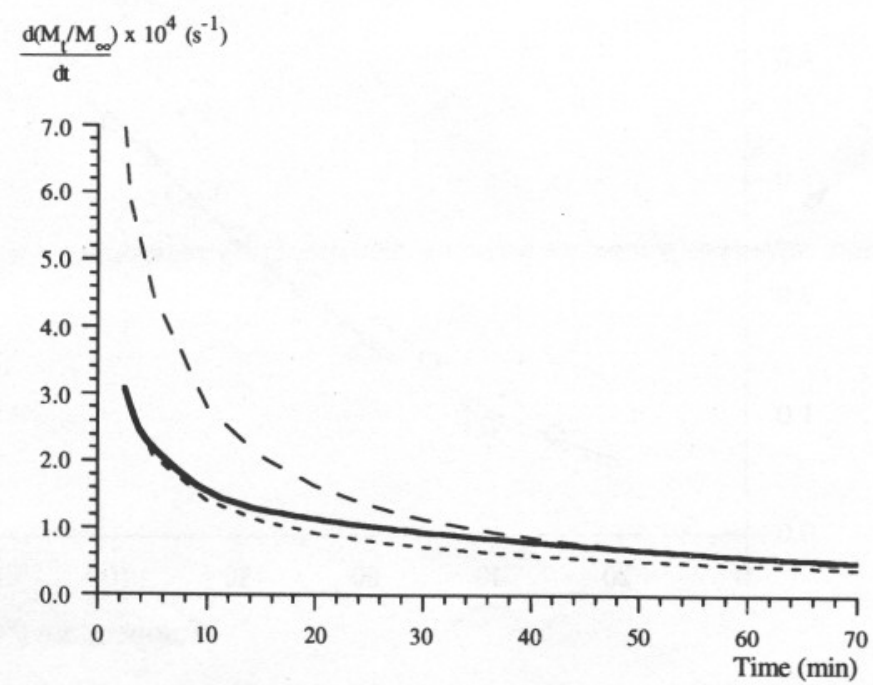

Figure 5. Diffusion rates under extreme isothermal conditions $\left(---20^{\circ} \mathrm{C}\right.$ and $\left.---100^{\circ} \mathrm{C}\right)$ and under non-isothermal conditions 
experiments (replicates) were $0.20,0.28$ and 0.22 . Fig. 4 shows one of the nonisothermal experiments. This confirms the conclusions drawn from the isothermal method i.e. the applicability of a simple Fickian diffusion with constant diffusivity at each temperature and a unit partition coefficient. The calculations were carried out using a temperature history corresponding to the arithmetic average between the temperature at the centre of the cube and the temperature of the bath. Due to the large dimension of the cubes, thermal lag resulted in these temperatures being generally significantly different (Fig. 1 shows an example). To check the accuracy of using an average temperature, similar calculations were performed for the temperature at the centre only and for the temperature of the bath only. The results were similar in all cases (the standard deviation relative to the average was under $1 \%$ ). Therefore the use of the average temperature was considered satisfactory. Alternatively, simultaneous heat and mass transfer could have been considered. This would have led, however, to a large increase in computational time requirements and this would be a major drawback of the method.

The dependence of the diffusion coefficient on temperature is also represented in Table 2. Values of $D_{0}$ and $E_{a}$ could be quite different (as can be seen in Fig. 6), but individual values of diffusivity at given temperatures were similar. For the higher temperatures the diffusivities predicted with the non-isothermal method parameters fell within the $90 \%$ confidence interval of the one step isothermal diffusivities. For the lower temperatures, this was sometimes not so, but values were always fairly close. This is related to the fact that the confidence interval increases with temperature. The difference in the individual values of $D_{0}$ and $E_{a}$ can be explained by the collinearity between them. This problem is also common to the isothermal method although most authors leave this unmentioned, especially when the parameters are obtained by a linear regression after application of logarithms to the Arrhenius equation (two step method). Fig. 6 shows the $90 \%$ joint confidence region for the estimates of the one step isothermal method. The extremes of this joint region correspond approximately to the $95 \%$ confidence intervals for individual parameters (Haralampu et al., 1985). This region is a much better representation of the estimates

Table 2. Diffusion coefficients estimated with the parameters obtained from the isothermal and nonisothermal methods

\begin{tabular}{|c|c|c|c|c|c|c|c|}
\hline \multirow[b]{3}{*}{$\mathrm{T}\left({ }^{\circ} \mathrm{C}\right)$} & \multicolumn{7}{|c|}{ Diffusion Coefficient $\times 10^{9}\left(\mathrm{~m}^{2} \mathrm{~s}^{-1}\right)$} \\
\hline & \multirow{2}{*}{$\begin{array}{l}\text { One step } \\
\text { isothermal }\end{array}$} & \multirow{2}{*}{$\begin{array}{l}\text { Lower } \\
\text { limit }^{\mathrm{a}}\end{array}$} & \multirow{2}{*}{$\begin{array}{l}\text { Higher } \\
\text { limit }^{a}\end{array}$} & \multirow{2}{*}{$\begin{array}{l}\text { Two step } \\
\text { isothermal }\end{array}$} & \multicolumn{3}{|c|}{ Non-isothermal replicates } \\
\hline & & & & & 1 & 2 & 3 \\
\hline 20 & $0.57^{\mathrm{b}}$ & 0.43 & 0.76 & $0.64^{\mathrm{b}}$ & $0.46^{\mathrm{b}}$ & $0.52^{\mathrm{b}}$ & 0.78 \\
\hline 30 & $0.76^{\mathrm{b}}$ & 0.69 & 0.97 & $0.84^{\mathrm{b}}$ & 0.62 & $0.69^{\mathrm{b}}$ & 0.99 \\
\hline 40 & $0.99^{b}$ & 0.84 & 1.23 & $1.07^{\mathrm{b}}$ & 0.83 & $0.92^{\mathrm{b}}$ & 1.24 \\
\hline 50 & $1.27^{\mathrm{b}}$ & 1.11 & 1.53 & $1.35^{\mathrm{b}}$ & 1.08 & $1.19^{\mathrm{b}}$ & 1.54 \\
\hline 60 & $1.67^{b}$ & 1.42 & 1.89 & $1.67^{\mathrm{b}}$ & 1.39 & $1.52^{\mathrm{b}}$ & $1.88^{\mathrm{b}}$ \\
\hline 70 & $2.01^{b}$ & 1.79 & 2.29 & $2.06^{b}$ & 1.75 & $1.91^{\mathrm{b}}$ & $2.27^{\mathrm{b}}$ \\
\hline 80 & $2.47^{b}$ & 2.14 & 2.88 & $2.49^{b}$ & $2.19^{\mathrm{b}}$ & $2.37^{b}$ & $2.72^{\mathrm{b}}$ \\
\hline 90 & $3.00^{\mathrm{b}}$ & 2.50 & 3.63 & $2.99^{b}$ & $2.70^{\mathrm{b}}$ & $2.91^{\mathrm{b}}$ & $3.22^{\mathrm{b}}$ \\
\hline 100 & $3.62^{b}$ & 2.88 & 4.58 & $3.56^{\mathrm{b}}$ & $3.29^{b}$ & $3.54^{\mathrm{b}}$ & $3.78^{b}$ \\
\hline
\end{tabular}

a $90 \%$ confidence interval limits for the one step isothermal method.

b Values which fall within the $90 \%$ confidence interval of the one step isothermal method. 


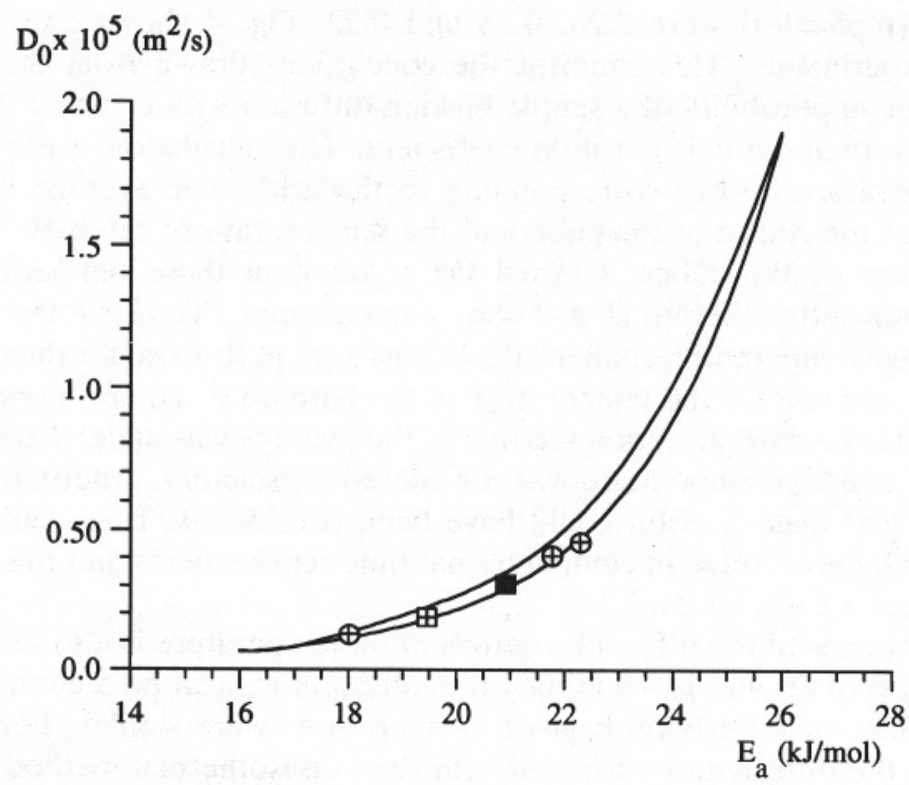

Figure 6. $90 \%$ joint confidence region for the estimates of $D_{0}$ and $E_{a}$, calculated from the one step isothermal method. Values calculated from all methods are shown: $\mathbf{m}$, one step isothermal; $\square$, two step isothermal; $\oplus$, non-isothermal (3 replicates).

than individual confidence intervals since it makes evident that the parameters are highly correlated. In order to express this point more clearly, the pairs of $D_{0}$ and $E_{a}$ obtained in the three non-isothermal runs are shown in Fig. 6. Given the objectives of this work, a high number of experimental points (210) was used for the isothermal methods, resulting in a narrow joint confidence region. Nevertheless, all pairs of $D_{0}$ and $E_{a}$ fell within or very close to the $90 \%$ confidence interval of the one step isothermal data. This region was calculated using the equation:

$$
\operatorname{Res}_{90 \%}=\operatorname{Res}_{\min }\left[1+\frac{\mathrm{P}}{\mathrm{N}-\mathrm{P}} \times \mathrm{F}_{90 \%}(\mathrm{P}, \mathrm{N})\right]
$$

This equation is actually only accurate for linear regressions, but it is a good approximation for the non-linear regressions normally used (Box et al., 1978).

A final indication of the accuracy of the non-isothermal method is given in Fig. 2, where the pairs of $D_{0}$ and $E_{a}$ obtained in the three non-isothermal runs are used to predict diffusion in some of the isothermal experiments. It can be seen that the predictions are quite good.

Although the non-isothermal method has proved to be accurate, some care must be taken in its application. In this case it has been applied on the basis of two assumptions: Fick's second law with a diffusivity depending only on temperature according to an Arrhenius behaviour, and equilibrium described by a constant unit partition coefficient. If one or both of these assumptions are not valid, the nonisothermal procedure does not allow for the identification of which one is wrong. An example is the existence of more than one diffusional period. For instance, Oliveira et al. (1992) have reported that Fick's second law applied only above $60^{\circ} \mathrm{C}$ in the leaching of reducing sugars from carrots. If the non-isothermal procedure had been 
applied (e.g. in the $20-80^{\circ} \mathrm{C}$ range), the correlation would not have been good along the whole range of temperatures. The model would be clearly wrong, but there would be no way of finding out exactly what the problem was without resorting to the constant temperature method or to a more fundamental approach. Therefore this method should not be used to verify the fundamentals of a given system.

\section{Conclusions}

The accuracy of the non-isothermal method has been demonstrated. Use of this procedure significantly reduces experimental requirements, and also thermal lag effects are minimized, this being particularly important at high temperatures.

\section{Acknowledgments}

The first author acknowledges financial support from Junta Nacional de Investigação Científica e Tecnológica. We thank the Centro de Formação Profissional de Vairão of the Ministry for Agriculture of Portugal for the supply of raw materials.

\section{References}

Box, G.E.P., Hunter, W.G. \& Hunter, J.S. (1978). Statistics for Experimenters: an introduction to design, data analysis and model building. Pp. 484-487. New York: John Wiley \& Sons.

Cohen, E. \& Saguy, I. (1985). Statistical evaluation of Arrhenius model and its applicability in prediction of food quality losses. Journal of Food Processing and Preservation, 9, 273-291.

Crank, J. (1979). Mathematics of Diffusion. 2nd edn. Pp. 56-60. London: Oxford University Press.

Garrote, R.L., Silva, E.R. \& Bertone, R.A. (1988). Effect of freezing on diffusion of ascorbic acid during water heating of potato tissue. Journal of Food Science, 53, 473-487.

Haralampu, S.G., Saguy, I. \& Karel, M. (1985). Estimation of Arrhenius model parameters using three least square methods. Journal of Food Processing and Preservation, 9, 129-143.

Kincal, N.S. \& Kaymak, F. (1990). Simultaneous diffusion and degradation of ascorbic acid in potato blanching. In: Engineering and Food. Vol. 1: Physical properties and process control, (edited by W. Spiess \& H. Schubert). Pp. 512-520. London: Elsevier Applied Science.

Labuza, T.P. \& Kamman, J.F. (1983). Reaction kinetics and accelerated tests simulation as function of temperature. In: Computer Aided Techniques in Food Technology, (edited by I. Saguy). Pp. 71-115. New York: Marcel Dekker, Inc.

Luna, J.A. \& Garrote, R.L. (1987). Prediction of vitamin $\mathrm{C}$ retention of potato strips blanched in water. Journal of Food Science, 52, 634-638, 672.

McCarthy, M.J. \& Heil, J.R. (1988). Measurement of acid diffusion in canned vegetables using $\mathrm{pH}$ sensitive indicators. Journal of Food Science, 53, 494-495, 499.

Moreira, L.A., Oliveira, F.A.R. \& Silva, T.R. (1992). Prediction of $\mathrm{pH}$ change in processed acidified turnips. Journal of Food Science, 57, 928-931.

Nelson, R.R. (1983). Stability prediction using the Arrhenius model. Computer Programs in Biomedicine, 16, 55-60.

Nunes, R.V., Rhim, J.W. \& Swartzel, K.R. (1991). Kinetic parameter evaluation with linearly increasing temperature profiles: integral methods. Journal of Food Science, 56, 1433-1437.

Oliveira, F.A.R. (1988). Mass Transfer Analysis for the Leaching of Water Soluble Components from Foods. Ph.D. thesis. University of Leeds, UK.

Oliveira, F.A.R. \& Silva, C.L.M. (1992). Freezing influences diffusion of reducing sugars in carrot cortex. Journal of Food Science, 57, 932-934.

Potts, E.A., Fleming, H.P., McFeeters, R.F. \& Guinnup, D.E. (1986). Equilibration of solutes in nonfermenting brined pickling cucumbers. Journal of Food Science, 51, 434-439.

Rhim, J.W., Nunes, R.V., Jones, V.A. \& Swartzel, K.R. (1989a). Determination of kinetic parameters using linearly increasing temperatures. Journal of Food Science, 54, 446-450.

Rhim, J.W., Nunes, R.V., Jones, V.A. \& Swartzel, K.R. (1989b). Kinetics of color change of grape juice generated using linearly increasing temperatures. Journal of Food Science, 54, 776-777.

Rice, P. \& Selman, J.D. (1984). Technical Note: Apparent diffusivities of ascorbic acid in peas 
during water blanching. Journal of Food Technology, 19, 121-124.

Rodgers, G., Hastings, R., Cryne, C. \& Bailey, J. (1984). Diffusion properties of salt and acetic acid into herring and their subsequent effect on the muscle tissue. Journal of Food Science, 49, 714-720.

Rogers, A.R. (1963). An accelerated storage test with programmed temperature rise. Journal of Pharmacy and Pharmacology, 15, supplement, Transations of the British Pharmaceutical Conference, Centenary Meeting London, Pp. $101 \mathrm{~T}-105 \mathrm{~T}$.

Schwartzberg, Y.G. \& Chao, R.Y. (1982). Solute diffusivities in leaching process. Food Technology, 36, $73-86$.

\section{Appendix}

\section{Nomenclature}

$\mathrm{C}_{0} \quad$ Initial concentration of acetic acid in the bath $\left(\mathrm{mol} \mathrm{m}^{-3}\right)$

D Diffusivity $\left(\mathrm{m}^{2} \mathrm{~s}^{-1}\right)$

D' Average diffusivity $\left(\mathrm{m}^{2} \mathrm{~s}^{-1}\right)$

$\mathrm{D}_{0} \quad$ Pre-exponential factor in the Arrhenius relationship between diffusivity and temperature $\left(\mathrm{m}^{2} \mathrm{~s}^{-1}\right)$

$\mathrm{E}_{\mathrm{a}} \quad$ Activation energy $\left(\mathrm{kJ} \mathrm{mol}^{-1}\right)$

$\mathrm{F}_{\mathrm{s} N \%} \quad \mathrm{~F}$ value for $90 \%$ confidence interval

$\mathrm{K}_{\mathrm{p}} \quad$ Partition coefficient (ratio between the concentration of acid in the food and in the bath at equilibrium)

subscript, varying from 1 to the number of points used in the regression

L Half-thickness of the cube (m)

$\mathrm{M}_{\mathrm{t}} \quad$ Acid intake at time $\mathrm{t}(\mathrm{mol})$

$\mathrm{M}_{\times} \quad$ Acid intake at equilibrium (mol)

$\mathrm{M}_{\mathrm{i}}^{\mathrm{e}} \quad$ Experimental acid intake at time $\mathrm{t}(\mathrm{mol})$

$\mathrm{N} \quad$ Number of experimental points

$P \quad$ Number of parameters (eqn 12)

$q_{n} \quad$ Non-zero positive roots of eqn (2)

$\mathrm{R} \quad$ Ideal Gas Constant $\left(8.314 \mathrm{~J}\right.$ mol. $\left.\mathrm{K}^{-1}\right)$

Res Residual between experimental and theoretical values (eqn 5)

$\mathrm{Res}_{\mathrm{s}) \%} \quad$ Residual between experimental and theoretical values for the $90 \%$ confidence joint region (eqn 12)

Res $_{\min } \quad$ Minimum residual between experimental and theoretical values (eqn 12)

T Temperature (K)

t Time (s)

$V_{\mathrm{b}} \quad$ Volume of the bath $\left(\mathrm{m}^{3}\right)$

$V_{p} \quad$ Volume of the cubes $\left(\mathrm{m}^{3}\right)$

$\alpha \quad$ Function of the fractional uptake, equal to the ratio between the amount of acid in the solution and in the turnip, at equilibrium

$\beta \quad$ Dummy variable, function of the temperatures used in the regression (eqns 7,8 and 9)

$\delta \quad$ Dummy variable in eqns 7 and 8 